\title{
No reduction in fibreoptic intubation rates with universal video laryngoscopy
}

\author{
Gareth Thomas, BMBCh $\cdot$ Fiona Kelly, MBBS $\cdot$ Tim Cook, MBBS
}

Received: 28 July 2015/Revised: 14 August 2015/ Accepted: 9 September 2015 / Published online: 30 September 2015

(C) Canadian Anesthesiologists' Society 2015

\section{To the Editor,}

We read with great interest Law et al.'s retrospective analysis of trends in the rates of awake fibreoptic intubation (FOI). ${ }^{1}$ We offer our own data that further confirm that the widespread use of video laryngoscopy (VL) - at even higher rates than reported by Law - does not impact the overall incidence of awake FOI. We have recently converted our anesthetic department (comprising 14 theatres) to one where the default intubation modality is VL. Although we already had access to the Storz C-MAC ${ }^{\circledR}$ VL in our theatre suites in 2012, the availability was limited, and VL was used purely as a rescue tool. By 2013, however, we transitioned to VL as the first-choice laryngoscopic modality, and throughout 2014, VL has been universally available and used in approximately $80 \%$ of in-theatre intubations. We plan to increase this to $100 \%$ in the near future.

Although we perform a smaller total number of intubations than QEII hospital (Table) and perform intubations in only a third of our general anesthetics, our rate of FOI per intubation is quite similar to that reported by Law and has not increased since our change to routine use of VL.

Law et al. concluded that, despite increased availability and use of VL, the rates of awake FOI had not significantly changed in their institution. Of importance, this is with a reported VL usage of only 8-10\%. In a different healthcare

This letter is accompanied by a reply. Please see Can J Anesth 2016; 63: this issue.

G. Thomas, BMBCh $(\bowtie) \cdot$ F. Kelly, MBBS - T. Cook, MBBS

Department of Anaesthesia and Intensive Care Medicine, Royal United Hospital, Combe Park, Bath, UK

e-mail: garethrthomas@doctors.org.uk
TABLE Rate of video laryngoscopy and fibreoptic intubation in bath vs QEII

\begin{tabular}{llllll}
\hline & $\begin{array}{l}2012- \\
\text { QEII }\end{array}$ & $\begin{array}{l}2012- \\
\text { Bath }\end{array}$ & $\begin{array}{l}2013- \\
\text { QEII }\end{array}$ & $\begin{array}{l}2013- \\
\text { Bath }\end{array}$ & $\begin{array}{l}2014- \\
\text { Bath }\end{array}$ \\
\hline Total Intubations & 12,875 & 3,300 & 13,541 & 4,497 & 4,072 \\
$\%$ VL & $8 \%$ & $\approx 10 \%$ & $10 \%$ & $\approx 80 \%$ & $\approx 80 \%$ \\
Awake FOI & 127 & 21 & 124 & 44 & 32 \\
$\%$ awake FOI & $0.99 \%$ & $0.64 \%$ & $0.92 \%$ & $0.98 \%$ & $0.79 \%$ \\
\hline
\end{tabular}

FOI = fibreoptic intubation; $\mathrm{VL}=$ video laryngoscopy

environment, we also discerned no change in the rates of awake FOI despite introducing universal availability and routine use of VL.

Funding None.

Conflicts of interest Our department has received numerous airway devices from manufacturers (including Ambu) either free or at reduced cost for evaluation or research. None of the authors declare any personal conflicts of interest.

\section{Reference}

1. Law AJ, Morris IR, Brousseau PA, de la Ronde S, Milne AD. The incidence, success rate, and complications of awake tracheal intubation in 1,554 patients over 12 years: an historical cohort study. Can J Anesth 2015; 62: 736-44. 